\title{
O CONSTRUTIVISMO INSTITUCIONAL E A DEMOCRACIA BRASILEIRA
}

\author{
Carlos Sávio G. Teixeira* \& Tiago Medeiros ${ }^{* *}$
}

\begin{abstract}
Resumo: O artigo analisa a relação entre a consciência institucional brasileira e a operação das instituições vigentes no país. A questão é abordada através da identificação de um problema prático: o que pode a democracia brasileira sob a clausura de uma mentalidade institucional limitada ao pretexto da estabilidade ou à fuga da responsabilidade de conceber e desenhar instituições? O percurso do argumento obedece a um desenvolvimento encadeado: i) a indagação a respeito de qual o principal problema da democracia brasileira; ii) O tratamento do tema em sua denotação teórica profunda e filosófica, passando em revista as alternativas de pensamento institucional disponíveis; iii) A observação de como o pensamento social e político brasileiro ordena os desafios institucionais do país e qual vertente deva ser resgatada; iv) E, por último, o retorno ao tema inicial, fechando o ciclo com a indicação de um rumo para a democracia brasileira em sua dimensão institucional, dadas as formas de pensamento existentes.
\end{abstract}

Palavras-chave: Democracia; Institucionalidade; Brasil.

\section{INSTITUTIONAL CONSTRUCTIVISM AND BRAZILIAN DEMOCRACY}

\begin{abstract}
The article examines the relationship between the Brazilian institutional consciousness and the current performance of Brazilian institutions. The analysis departs from a practical problem: what can Brazilian democracy do, closed by a particular intellectual setting under the pretext of maintaining political stability, and running away from the responsibility of conceiving and designing new institutions? The argument follows a series of connected steps: (i) the question about the main problem of Brazilian democracy; (ii) the question about its theoretical and philosophical underpinnings, considering alternative lineages of institutional thought; (iii) the question about how Brazilian social and political thought molds national institutional challenges and which streams of Brazilian thought should be revived; (iv) and, finally, the claim of a new path for Brazilian democracy in its institutional form, considering existing and available modalities of thought.
\end{abstract}

Keywords: democracy; institutions; Brazil.

\section{EL CONSTRUCTIVISMO INSTITUCIONAL Y LA DEMOCRACIA BRASILEÑA}

\footnotetext{
* Doutor em Ciência Política pela Universidade de São Paulo (USP) e Professor do Departamento de Ciência Política da Universidade Federal Fluminense (UFF), Brasil. ORCID: https://orcid.org/0000-0001-8877-5537. Contato: carlos.savio.teixeira@gmail.com

${ }^{* * *}$ Doutor em Filosofia pela Universidade Federal da Bahia (UFBA) e Professor de Filosofia do Instituto Federal da Bahia (IFBA), Brasil. ORCID: https://orcid.org/0000-0001-8157-4564. Contato: tiagomedeiroscontato@gmail.com
} 
Resumen: El artículo analiza la relación entre la conciencia institucional brasileña y la operación de las instituciones vigentes en el país. La cuestión es abordada a través de la identificación de un problema práctico: ¿lo que pode la democracia brasileña bajo a clausura de una mentalidad institucional limitada al pretexto de la estabilidad o a la fuga de la responsabilidad de concebir y diseñar instituciones? El recorrido del argumento obedece a un desarrollo encadenado: i) la indagación acerca de cuál el principal problema de la democracia brasileña ii) El tratamiento del tema en su denotación teórica profunda y filosófica, pasando en revista las alternativas de pensamiento institucional disponibles; iii) La observación de como el pensamiento social y político brasileño ordena los desafíos institucionales del país y cual vertiente deba ser rescatada; iv) Y, por último, lo retorno al tema inicial, cerrando el ciclo con la indicación de un rumbo para la democracia brasileña en su dimensión institucional, dadas las formas de pensamiento existentes.

Palabras clave: Democracia; Institucionalidad; Brasil.

\section{0 problema político: a democracia brasileira e as promessas irrealizáveis}

O principal problema da democracia brasileira hoje é o contraste entre as promessas inscritas na Constituição de 1988, cuja dimensão programática anuncia discursivamente a superação da subcidadania no país, e o fracasso em pôr em prática a solução de nossos gravíssimos problemas sociais. Há uma quase incomunicabilidade entre o sistema político e a sociedade. O sistema não consegue ofertar políticas públicas que, mesmo de forma incremental, satisfaçam à vontade da maioria dos brasileiros. Em todas as áreas, predomina a frustração ante as intervenções feitas pelo Estado e os serviços por ele entregues. O que varia é apenas o grau de insatisfação nas distintas áreas.

É esse o combustível das crises por que passa sistematicamente o nosso regime político. Contudo, não sendo tal problema sequer percebido com a clareza necessária pelos porta-vozes da consciência institucional vigente no país, os atores do sistema político e os intérpretes e analistas que o observam são reincidentes na promoção de diagnósticos carregados de equívocos e de soluções para problemas inexistentes. As crises institucionais no Brasil não têm suas raízes no regime presidencialista em que se baseia o nosso arranjo institucional da esfera política, o que não exclui que mudanças sejam vislumbradas em seu design para melhor relacioná-lo aos demais domínios da sociedade.

Do ponto de vista da institucionalidade política, uma parte considerável desta consciência (expressa em políticos, acadêmicos, jornalistas e juristas) identifica no regime presidencialista a causa de nossas crises constantes. A confusão reside na suposição de que o formato da gestão do sistema político pode aplacar as insatisfações da maioria da sociedade com o conteúdo precário da oferta insatisfatória de políticas públicas operadas pelo sistema 
político. É como se numa estrada toda esburacada a questão central fosse a mudança do tipo de câmbio que o automóvel possui, de manual para automático.

Desse cenário resultam as duas principais posturas político-institucionais do país no período da chamada Nova República. A parte majoritária da elite deseja pôr fim aos solavancos rotineiros representados pela eleição presidencial - eleição de cujo desfecho nunca se tem garantia. Vem daí a sempre ressuscitada proposta de adoção do parlamentarismo "para acabar com as crises políticas". O regime parlamentarista cassaria a soberania popular e concentraria todo o poder na classe política, justamente o principal ator do sistema, incapaz de ofertar o que a sociedade aspira. Essa é a única proposta de reforma, extraída do que chamaremos adiante de imanentismo institucional ralo, para o Brasil. Como uma espécie de derrota ideológica fulgurante, os seus defensores abandonaram o termo parlamentarismo e vêm adotando agora o vocábulo do semipresidencialismo.

Se, no campo liberal, a aposta é aumentar o filtro na relação entre a maioria e o sistema político, no campo da esquerda convencional, a confusão interpretativa diante de nossa crise sócio-política é ainda maior. Em vez de propor a restrição institucional em soluções como o parlamentarismo, o seu discurso aposta em extrapolar ou rejeitar a institucionalidade política existente e marchar na direção do que chamaremos de panconflitivismo: já que o sistema político não oferta o que a maioria espera, que se organize o protesto, intensificando os gritos e refinando as denúncias contra a inépcia do sistema e os reprodutores de sua lógica - então tidos, necessariamente, como sócios na opressão.

No lugar de um programa institucional com iniciativas reorganizadoras da estrutura abstratamente criticada, esse ativismo progressista crê na capacidade de dissolução das resistências do sistema pelo espontaneísmo dos movimentos sociais. É como se a saída não precisasse de passar pelo "piloto automático" do parlamentarismo, mas, ao contrário, pelo câmbio manual do militante que se aduz melhor condição de "controlar o automóvel" na estrada esburacada.

No Brasil contemporâneo, as mais celebradas correntes de pensamento dedicadas a analisar e propor soluções institucionais não vislumbram respostas para essa estrada. Elas tomam as deformações da pista como um dado, ou a esquecem como quem aceita a fatalidade do destino, atitude viciada que só pode animar à crise brasileira. A elite defensora do parlamentarismo naturaliza o quadro dramático da ineficácia do sistema político e imagina, quando muito, modestos ajustes marginais para lidar com suas consequências. Já a esquerda convencional, refém das próprias abstrações intelectuais, associa a negação da capacidade 
institucional instalada à defesa da parte compensatória do programa da ordem existente. Ambas, a elite liberal defensora do status quo, sem as crises do regime político, e o esquerdismo conservador, dedicado a pôr o pobre no orçamento sem tirá-lo da pobreza, acabam por trafegar, mesmo em veículos diferentes, sobre a mesma pista esburacada.

O problema principal do Brasil, a princípio uma dificuldade de conferir facticidade à generosidade constitucional, é adensado por duas ideologias, na aparência, hostis uma à outra; mas, na prática e nas premissas, cúmplices. Convém examinar os traços da consciência institucional predominante do país por meio de uma interpretação de suas alegações mais frequentes. À luz de um enquadramento filosófico e teórico-social que discuta a institucionalidade, poderemos retornar ao problema prático que agrilhoa a nossa democracia e oferecer uma solução geral e uma específica para enfrentá-lo.

\section{0 problema teórico: a consciência institucional e o pensamento político e} social contemporâneo

A consciência institucional que articula os discursos, as análises, a militância, as agendas políticas e a jurisdição no país encontra um número pequeno de expressões. A rigor, só tem predominado duas maneiras de pensar as instituições: ou se as concebe como um sistema funcional, desenhado para contemplar toda a variedade de demandas sociais de forma neutra e impessoal; ou se as concebe como conglomerados de artifícios que reproduzem, praticam e sacramentam desigualdades e injustiças históricas residuais. A primeira maneira de pensar é predominante entre setores da elite política, da imprensa e da academia nas Ciências Sociais Aplicadas, como o Direito e a Economia. A segunda, abunda nas disciplinas acadêmicas associadas às Humanidades, bem como onde o pensamento criticista e desconstrucionista conseguiu prosperar. Parte dos políticos profissionais e do jornalismo de opinião tenta fazer combinações de ambas as concepções - uma miscelânea que só tem servido para pintar a melancólica paisagem institucional que nos sobrou.

Entre essas duas consciências tem regido o país a primeira, aquela que segue a linha do que denominamos institucionalismo imanentista. Trata-se de um tipo de pensamento e programa de ação que repousa sobre a crença de que o ordenamento institucional de uma sociedade deve realizá-la inibindo as ameaças de instabilidade que qualquer sociedade tende a criar contra si mesma. Instituições sérias existem para impedir tombos, rupturas e solavancos, e garantir que a sociedade não sofra os reveses das interações sociais desviantes. Por isso, devem as instituições ser talhadas à força, à resiliência e à elasticidade (se não 
puderem conter rigidez); afinal, a função do sistema de instituições é a produção de estabilidade. As instituições seriam, portanto, entes estáveis capazes de oferecer estabilidade às interações a que elas se prestam como articuladoras. Tal consciência é institucionalmente conservadora, porque limita o escopo do institucional às coisas que não estão sujeitas à mudança.

O institucionalismo imanentista atravessou todo o pensamento político moderno ocidental. Passou por diferentes momentos históricos, em que se foi preciso justificar a existência de determinadas instituições, buscando suas raízes em práticas e consciências sociais profundas. Consideremos em poucos e meramente ilustrativos aspectos a dimensão institucional do pensamento de Hegel, o maior expoente do institucionalismo imanentista. Pode-se dizer que o seu projeto institucional consistia em recompor o lugar das instituições que vigoravam na Europa de seu tempo: a família monogâmica, a propriedade privada, as corporações de ofício, a sociedade civil-burguesa, o direito positivo, o Estado-nação etc, em um todo coerente e necessário, entendendo-as como objetivação do espírito - a efetividade pelos modos de ação convencionados, os quais lhe pareciam fazer-se necessários ao indivíduo singular pelo costume ${ }^{1}$. O que Hegel realizou foi a elevação do patamar de universalidade de uma experiência nacional, oferecendo à humanidade como um todo o que se lhe afigurava próspero na Prússia de início do século XIX.

O caráter de uma totalidade em movimento com que Hegel pensa o espírito engendra uma ideia de institucionalidade em consonância com a multiplicidade expressiva do volume de ações de um povo cristalizadas nas práticas que lhes são ordinárias. Tem-se assim a adoção de uma abordagem ontológica da institucionalidade como uma coisa fluida e ativa, espontânea e anônima, e sobretudo plural, mas identificada à sua consumação no presente, reduzindo o possível ao existente. Desde Hegel, o que passa a ter importância é a construção da experiência institucional, que entrelaça as dimensões, histórica, política, psíquica, econômica e jurídica da condição humana moderna em uma mesma trama, a trama do agora.

No Brasil, contudo, não houve o desenvolvimento do institucionalismo imanentista nessa forma densa e robusta. Ele foi, na verdade, misturado a uma atitude epistêmica e comportamental que caracteriza, de há muito, as elites nacionais no que diz respeito ao país

\footnotetext{
${ }^{1}$ Ver HEGEL, G.W.F. Linhas Fundamentais da Filosofia do Direito. São Leopoldo, Ed. Unisinos, 2010, § 151, p. 171-172.
} 
que elas lideram, o colonialismo mental ${ }^{2}$. Como o desenho da institucionalidade política foi, ao menos desde a Proclamação da República, dependente da importação de instituições exitosas no Atlântico Norte, as nossas instituições, ou sua maior parte, não foram feitas para refletir as demandas reais e profundas de nossa sociedade, mas para determinar que sociedade o Brasil deveria ser, que aspirações o seu povo deveria ter, que objetivos sociais ele deveria perseguir. Essa institucionalização exógena, como se verificou e tem se verificado, não pode assegurar a estabilidade desejada; ao contrário, a tentativa de conviver com pacotes institucionais de alhures só tem redundado em crises sistêmicas, sintomatologia recorrente desde muito antes da Constituição de $1988^{3}$.

$\mathrm{O}$ institucionalismo imanentista combinado, à brasileira, com o colonialismo mental resulta em uma substância rala, anêmica, sem fibra - uma caricatura do que é a institucionalidade da vida de um povo. Totalmente desligado da sociedade brasileira e desinteressado por suas características, potências, virtudes, defeitos e vontades, o nosso imanentismo ralo ainda tem sido, contudo, a base do pensamento e do programa de ação de nossos quadros dirigentes, razão pela qual os nossos impasses institucionais são, ao mesmo tempo, teóricos e práticos.

A performance mais explicita da mentalidade colonial brasileira está na adoção irrefletida de práticas, métodos e formas institucionais fetichizados. A verdade é que, no Brasil, o fetichismo institucional prevalece, tanto nos domínios do pensamento quanto nos da ação, graças a uma percepção estreita que associa um repertório já conhecido de instituições ao acesso imediato e felicitante aos mais altos valores e princípios da vida social.

O fetichismo é o que restringe o conteúdo de uma instituição a um rótulo que ela anuncia de forma simples e inapelável. O problema é que ele inviabiliza o debate a respeito

\footnotetext{
${ }^{2}$ Extraímos a noção de colonialismo mental de Roberto Mangabeira. Convém um trecho em que o autor esclarece como o colonialismo mental opera: "As ideias a respeito da estrutura da sociedade, de sua possível transformação e dos imperativos e alternativas institucionais são fixadas, sob o reino do colonialismo mental, por correntes de pensamento dominantes nos países orientadores. A cultura popular fica desligada de qualquer ideário ou projeto voltado para a reconstrução da sociedade e de suas instituições. E na medida em que se torna objeto das preocupações da alta cultura, sobretudo da cultura acadêmica, vira folclore.” UNGER, Roberto Mangabeira. Depois do Colonialismo Mental: Repensar e reorganizar o Brasil. São Paulo, Autonomia Literária, 2018, p. 19.

${ }^{3}$ Não seria inoportuno explorar, ainda no domínio do colonialismo mental, com atenção a essa antecedência histórica, o efeito "psicológico" da formação colonial da sociedade brasileira, para cujo enquadramento recorremos a Alberto Guerreiro Ramos: "A situação colonial, posta em questão hoje por sociólogos e economistas, é entendida como um complexo, uma totalidade que impõe certo tipo de evolução e de psicologia coletiva às populações colonizadas. Um dos traços desta psicologia coletiva é a dependência, certo bilingüismo, a duplicidade psicológica, condições que tornam limitadíssima a possibilidade de uma identificação da personalidade do colonizado com a sua circunstância histórico-natural imediata" RAMOS, Alberto Guerreiro. Introdução Crítica à Sociologia Brasileira. Rio de Janeiro, Ed. UFRJ, 1995, p. 37.
} 
da reorganização e da oferta de novos termos relativos ao pensamento e às práticas institucionais. Tomando qualquer instituição pelo que abrevia o seu invólucro, a capacidade de fazer dela resultado da vontade e da autonomia humana reduz-se sobremaneira. Trocando em miúdos, o fetichismo termina por ser uma performance acadêmica e governamental que naturaliza as formas de instituição em um conjunto pequeno de assunções e regras, de arranjos produtivos e associativos, mediocrizando a experiência coletiva e as alternativas de organização social por meio de instrumentos ideológicos e jurídicos limitados e limitantes, e camuflando essa limitação com ares de virtude. Isso implica em naturalizar ou racionalizar a realidade social em um suposto pacto geral ${ }^{4}$.

A resposta ao pensamento e à agenda imanentistas, no mais das vezes, tem sido encabeçada por gente que não assume qualquer compromisso institucional, a saber, com a criação, o desenho, a construção de instituições. Trata-se de uma atitude escapista e antiinstitucional, porém predominante nas universidades e no jornalismo alternativo, e autoproclamada progressista ou de esquerda, ambientes em que a atitude anti-institucional adquire tons de altivez e elegância. Ela recorre aos métodos do criticismo e do descontrucionismo, enaltecidos como trunfos empoderadores e emancipatórios, para esconder a completa falta de imaginação criadora, diante das aporias que a nossa relação histórica com as instituições nos legou. Sedimentou-se no imaginário desses grupos que as instituições são constructos históricos a serviço e para prestígio das elites políticas e econômicas que as criaram. A isso acrescentou-se a crença de que tais elites praticam invariável e acintosamente a exclusão social das minorias condenadas às pressões de qualquer ordenamento institucional.

Sob o peso dessa premissa, a agenda ativista da elite intelectual autointitulada progressista encara um dilema: não dá para aceitar essas instituições, mas não é factível que vivamos num mundo sem elas. Logo, a tarefa desconstrucionista e criticista encontra a sua

\footnotetext{
${ }^{4}$ Esse é um dos temas explorados na trilogia de teoria social e política de Roberto Mangabeira Unger, publicada em 1987 sob o título geral de Politics - A Work in constructive social theory. Trata-se de uma teoria social orientada por uma agenda programática da política voltada para organizar um esquema conceitual e uma narrativa intelectual que realize o valor politicamente expressivo da democracia radicalizada. O fetichismo institucional apela a uma ideia de necessidade falsa, embora goze de prestígio tanto nos discursos liberais quanto nos marxistas. Em suas palavras: "O fetichismo institucional contamina as ideias liberais e esquerdistas mais familiares. O liberal típico identifica erroneamente um conjunto específico de compromissos improvisados de organização das democracias representativas e das economias de mercado com a própria natureza de uma democracia livre e da ordem de mercado. O marxista ortodoxo subsume esses mesmos arranjos institucionais singulares a um tipo genérico de organização social, que supostamente representaria um estágio bem definido da história mundial. Exime-se, assim, da necessidade de descrever em detalhe o estágio seguinte, socialista, da evolução social”. UNGER, Roberto Mangabeira, Social Theory. Its situation and Its Task. Cambridge, Cambridge University Press, 1987, p. 12, tradução nossa do original.
} 
razão de ser na acusação das instituições e práticas que reproduzem vícios históricos, tomando por norte a denúncia dos sofrimentos humanos refletidos na institucionalidade e contentando-se com os resultados barulhentos - ainda que infecundos - desse expediente ativista. A revolta praticada e promovida por essa militância é eficaz em mobilizar aqueles a quem ela promete proteção e a seus simpatizantes de causa, comumente movidos por um agudo ressentimento. Na ausência do que construir, todos vão ao conflito. Por isso, esse antiinstitucionalismo é pan-conflitivista: o que importa para ele é ter um adversário, não uma ideia sobre o que fazer.

Ao desistir do debate institucional, o anti-institucionalismo pan-conflitivista, que se apresenta como consciência alternativa à consciência institucional vigente, subscreve o institucionalismo imanentista ralo prevalecente. Quem acaba por pensar e falar em instituições, pensa e fala no truísmo da estabilidade. Ao fim do dia, permanece recaindo sobre um judiciário abarrotado a tarefa de dar amarras ao que a cultura enche de incentivos. As aventuras de mudança do sistema político para o parlamentarismo ou o semipresidencialismo, bem como a evocação de uma assembleia constituinte, são variantes do mesmo princípio: já que esse sistema ou essa Constituição não conseguem domar e disciplinar o povo, os troquemos por outros.

\section{A alternativa teórica: o transcendentismo institucional - um outro caminho} para pensar as instituições

As duas alternativas de tratamento das instituições descritas acima não são as únicas. O pensamento filosófico ocidental despertou para um viés que não admite a centralidade conservadora na estabilidade e rechaça, de forma ainda mais veemente, a atitude anti-institucional, o conservadorismo em pele de revolução. Esse viés sustenta que é possível mudar as condições materiais de vida através das instituições, mudar com instituições que mudem. Para isso, há que se refazer a própria atitude ou a relação entre os indivíduos e grupos e as instituições que os conectam. Essa relação precisa ser movida pela imaginação institucional, a capacidade de recombinar as peças da realidade, em sua dimensão prática e jurídica, formando um conteúdo institucional novo. Pensando que as instituições não são um sistema de reprodução espontânea da consciência de um povo, mas concebendo-as como artefatos que permitirão a esse povo ir além de suas circunstâncias, o conjunto de teses solidárias a esse princípio nós chamamos de institucionalismo transcendentista, ou transcendentismo institucional. 
De um ponto de vista filosófico, a diferença essencial entre o institucionalismo imanentista que vigora no Brasil e a sua oposição real mobilizada no institucionalismo transcendentista é a de duas formas de pensar as raízes da institucionalidade, isto é, a predisposição humana a criar e conservar, a ser entre e através de, instituições. As duas formas admitem a institucionalidade como parte do fenômeno mais amplo da ordem social. A institucionalidade torna-se para ambas um problema cuja solução requer uma crítica racional reveladora do conteúdo universalmente válido sobre a ordem. A questão é a respeito da validade dos acordos criados para organizar a vida social: se tal validade poderia ser negada, o que convidaria a rupturas, ou confirmada, o que resultaria em conservação ${ }^{5}$.

A fim de esclarecer ainda mais o componente filosófico de nosso argumento, tomemos os dois institucionalismos pelas imagens que eles costumam criar para expressar a institucionalidade. A primeira imagem revela que as instituições são realidades proeminentemente consistentes e ubíquas: conquistas coletivas demoradas, tornadas convenções, e apoiadas em pilares éticos. Nesse caso, elas são bem descritas como um patrimônio coletivo anônimo, que serve de referência para a orientação da conduta e as tomadas de decisão relativamente a interesses comuns - não há estabilidade social na ausência de instituições estáveis ${ }^{6}$. A segunda, revela objetos predominantemente evanescentes e solúveis, porque erigidas sob o condão da intencionalidade humana ao fim de conflitos circunscritos e datados. Essa imagem mostra o que cada reformador ou revolucionário social está disposto a, respectivamente, inaugurar ou derrubar, com o objetivo de aperfeiçoar a sociedade - não há ruptura social que não passe pela substituição de um conteúdo institucional por outro ${ }^{7}$.

A diferença conceitual mais penetrante insinuada por trás dessas duas imagens é de ênfase. A primeira imagem enfatiza a necessidade implícita às formas duradouras de interação. A segunda enfatiza a contingência explícita das relações humanas. A categoria modal da contingência remete à experiência de indeterminação, de acordo com a qual não

\footnotetext{
${ }^{5}$ Sobre a relação entre a teoria social do Iluminismo e a ideia de legitimação das instituições, ver MERQUIOR, J.G. Rousseau and Weber: Two Studies in the Theory of Legitimacy. London, Routledge \& Kegan Paul Ltd., 1980, p. 9-13.

${ }^{6}$ Uma manifestação extrema dessa visão, como a proposta por Émile Durkheim, toma o social como uma entidade quase mística que detém um conteúdo moral intrínseco.

${ }^{7}$ Uma manifestação extrema dessa perspectiva nega a própria importância da institucionalidade e não oferece uma teoria das instituições em resposta. Esse é o caso de Karl Marx. Um exemplo notável está na falta de uma teoria do Estado e da democracia socialistas, que deveriam emergir após às críticas ao Estado capitalista e à democracia burguesa. Norberto Bobbio anota com argúcia que toda a base da institucionalidade liberal foi pensada antes das revoluções burguesas. Ver BOBBIO, N. Qual Socialismo? Discussão de uma alternativa. Rio de Janeiro, Paz e Terra, 1983, p. 24.
} 
há nada no objeto contingente que testemunhe a sua existência, ou a sua ocorrência fenomênica, enquanto fundamento consistente e imperecível, contínuo por essência e não por acaso. A categoria modal da necessidade remete à autossubsistência do objeto ou fenômeno em tela: há irrevogavelmente algo por trás ou abaixo que o suporta, algo cuja negação explicitaria uma contradição insustentável.

Em um plano de assuntos eminentemente sociais e políticos, como esse em que as instituições são pensadas, ao se priorizar a contingência, respalda-se uma ideia de emancipação pelos expedientes do empoderamento ou da autonomia, quer individual, quer social, para daí derivar a legitimação da institucionalidade. Ao se prestigiar a necessidade latente ao institucional, enfatiza-se a adaptação da autonomia à legitimidade, pretendendose que aquela só se realize nesta, ou que imprescindivelmente a confirme.

O institucionalismo transcendentista se pauta pelos exemplos históricos de criação de instituições. Cada instituição tem uma origem na vontade e na deliberação humanas, em sociedades e contextos históricos sempre específicos e nunca repetidos. Portanto, mesmo que copiadas, as instituições são sempre únicas em seu conteúdo e em sua implementação, porque são desenhadas por indivíduos com interesses e ideais que reconhecem a facticidade das sociedades a que se prestam como articuladoras nas próprias sociedades. Essa tese da origem histórica e deliberada das instituições, por oposição a uma tese que enfatiza seu surgimento enquanto espontâneo e anônimo, tem importantes desdobramentos e exemplos. As Conferências da Filadélfia e o New Deal americanos, ou a Assembleia Constituinte de 1988 brasileira, são mostras de que a institucionalidade é concebida, desenhada, desenvolvida, testada e aprimorada em resposta a demandas conjunturais que não fecham o futuro da sociedade. Essa tese dá o tom do institucionalismo transcendentista, para o qual as instituições têm suas raízes inequivocamente na deliberação e na vontade de indivíduos de carne e osso, e nunca na autorrealização de um etéreo espírito do tempo.

A tese acima já seria suficiente para desfazer a hipótese de que as instituições poderiam funcionar automaticamente. Afinal, se não surgem como autômatos, muito menos poderiam alçar a condição de autônomas. Além disso, convém asserir que elas têm sua substância na mais contaminada das atividades humanas, a política. É a política, enquanto conjunto de ações recíprocas que costuram interesses em conflitos e consensos, a própria matéria da institucionalidade em qualquer domínio da vida social.

A essência política das instituições não só esclarece a tese da origem deliberada indicada antes, como também consagra à institucionalidade a condição de contingência. A 
política, como as guerras, as crises econômicas, as tragédias ambientais e os conflitos migratórios, revela o quão a história é vulnerável a inflexões. A história não é escrita por um roteirista presciente das realidades de além do agora, mas por pessoas com aspirações e vicissitudes que a estampam nas instituições - artefatos contingentes e imaginados que são tão mais equilibrados com as sinuosidades da história quanto mais plástica for a sua substância. Assim, o terceiro tema caro ao transcendentismo é o reconhecimento e a aposta na plasticidade institucional.

Em linhas muito simples, o filósofo Roberto Mangabeira Unger define plasticidade:

Por plasticidade entenda-se a facilidade com que as relações de trabalho entre pessoas - em uma fábrica, em um escritório, em um exército - podem ser constantemente alteradas em resposta a circunstâncias, recursos e propósitos mutáveis. Plasticidade é a oportunidade para inovar nos cenários intermediários da produção, das trocas, da administração ou da guerra e fazê-lo não apenas quando das grandes reformas ocasionais, mas por um fluxo contínuo, cumulativo de inovações em pequena escala. Conforme esta visão de plasticidade, a vantagem do controle rígido ou dos esquemas de extração do excedente superam os benefícios da plasticidade apenas em níveis relativamente baixos de disponibilidade de recursos e de sofisticação tecnológica. ${ }^{8}$

A busca pela plasticidade institucional é muito mais importante do que o sonho da elasticidade institucional, ou seja, o desejo de que as instituições sejam fortes e resilientes, sendo também, e por assim dizer, esticáveis para lá ou para cá. Um imanentista, quando não pode sustentar a rigidez das instituições, apela à elasticidade com que pretende que elas se as estendam, sem romper seu tecido, sem sofrer fissuras, face às surpresas da vida social e política. Um transcendentista, ao contrário, em vez de reivindicar o atributo da elasticidade, adota a plasticidade, pela exata razão do que nos afirma Mangabeira Unger no parágrafo acima. A virtude que acompanha as mudanças é a disposição para também mudar, não a capacidade de contemplar, ao limite do possível, como uma substância elástica e homogênea, por dilatação, a heterogeneidade da sociedade e de sua história.

\section{A alternativa prática: $O$ construtivismo institucional e suas contribuições}

\footnotetext{
${ }^{8}$ Tradução nossa do original: "By plasticity I mean the facility with which work relations among people - in a plant, in a bureau, in an army - can be constantly shifted in order to suit changing circumstances, resources, and intentions. Plasticity is the opportunity to innovate in the immediate organizational settings of production, exchange, administration, or warfare and to do so not just by occasional, large-scale reforms but by an ongoing, cumulative flow of small-scale innovations. According to this thesis of plasticity, the advantages of rigid control or surplus-extraction schemes outweigh the benefits of plasticity only at relatively low levels of resource availability and technological sophistication." UNGER, Roberto Mangabeira. Plasticity into Power: Comparative-Historical Studies on the Institutional Conditions of Economic and Military Success. Cambridge, Cambridge University Press, 1987, p. 153-154.
} 
Na história do pensamento social e político brasileiro, a oposição entre esses institucionalismos nunca tomou uma forma em que fossem nítidos seus contrastes filosóficos. Mas a existência de um imanentismo ralo - a busca pela estabilidade institucional através da cópia - e de um pan-conflitivismo anti-institucional - a fuga criticista da responsabilidade de criar instituições factíveis -, tais como os descrevemos, reflete um movimento de ideias cujo desenrolar revela maior ou menor solidariedade às premissas filosóficas tratadas na seção anterior. Para que consigamos visualizar a operação prática daquelas máquinas teóricas, mensurando as respectivas considerações sobre as instituições na trajetória das ideias sociais e políticas brasileiras, proporemos uma tipologia do pensamento nacional capaz de hospedar cada uma das atitudes e temperamentos institucionais predominantes no país. À luz desse empreendimento tipológico, haveremos de poder aferir qual nos parece a perspectiva melhor equipada para realizar as potencialidades nacionais em um projeto de abordagem e revigoramento das instituições.

Há três grupos de ideias em disputa no imaginário social e político brasileiro, ao menos desde a Declaração da Independência (1822). Mas foi apenas em fins do século XIX e principalmente após a Revolução de 30, no século passado, que eles forjaram suas fronteiras e incompatibilidades recíprocas. Cada um desses grupos teve atores políticos e intelectuais conspícuos, que ajudaram a demarcar, na ação e no pensamento, o escopo de consistentes propostas de interpretação e intervenção no Brasil. Por motivos ligados a afinidade teórica e a circunstância histórica, optamos por nomeá-los de liberalismo culturalista, estruturalismo sociológico e construtivismo institucional. Com a redemocratização, cada um desses grupos conseguiu imprimir sua agenda em um partido político de sucesso eleitoral.

O liberalismo culturalista tem duas versões nativas: a psicossocial, que advoga a tese do personalismo como elemento-chave de nossa ordem social, e a institucional, que sustenta que o maior problema do país é o seu patrimonialismo endêmico, organizado em torno do estamento burocrático que controla o Estado e mina a capacidade de desenvolvimento do livre-mercado entre nós - um contraexemplo do que teria se dado nos EUA. A base dessa visão é a de que a nossa formação histórica foi dominada por uma herança de ideias, práticas e instituições advindas do mundo ibérico que precisam ser removidas. Na programação político-institucional, a sua inspiração é o federalismo de cepa 
norte-americana e o constitucionalismo liberal, tendo na questão da representação política e da autonomia da chamada sociedade civil contraposta ao Estado seus eixos principais. ${ }^{9}$

O estruturalismo sociológico tem como sua principal ambição explicar o advento da ordem social capitalista e sua estruturação no Brasil. É um paradigma que quase sempre foi dominado pela tradição marxista e sediado fundamentalmente em São Paulo. A sua tarefa analítica centrou-se no esforço de revelação da dinâmica de nossa "revolução burguesa", percebida sempre em termos negativos. Um de seus desdobramentos tem sido uma sociologia que se ocupa fortemente da denúncia dos processos de exclusão social derivados da forma de organização e funcionamento da sociedade de classes no Brasil. O seu programa político institucional oscila entre a proposta de revolução e a de democracia social sem, contudo, ser capaz, como seus congêneres europeus, de escapar do estatismo e do corporativismo como os arranjos institucionais que, na prática, acabam traduzindo suas ideias abstratas, como a de socialismo. ${ }^{10}$

A terceira grande corrente de pensamento de nossa tradição intelectual, o construtivismo institucional, teve desde sempre como foco de atenção analítica o processo de constituição da nação - partindo da crítica das instituições e práticas transplantadas em uma sociedade oligárquica e insolidária -, propondo a superação do colonialismo mental por meio de um método de compreensão da relação entre ideias e instituições apropriado a uma sociedade ainda subdesenvolvida. No programa político institucional, o acento na

\footnotetext{
${ }^{9}$ Esta corrente de pensamento é integrada por autores como Tavares Bastos, Rui Barbosa, Sérgio Buarque de Holanda, Raimundo Faoro e Roberto DaMatta. Para uma exposição sistemática a respeito desta tradição intelectual, ver VIANNA, Luis Werneck. A Revolução Passiva: Iberismo e americanismo no Brasil. Rio de Janeiro, Revan, 1997 e, para uma defesa dela, LAMOUNIER, Bolívar. Formação de um pensamento político autoritário na Primeira República: uma interpretação. In: FAUSTO, Boris (org.). História geral da civilização brasileira: tomo 3: O Brasil republicano: volume 2. São Paulo, Difel, 1985. Para uma crítica relativa ao déficit sociológico deste paradigma explicativo do Brasil e suas consequências ideológicas, ver SOUZA, Jessé. A ralé brasileira: quem é e como vive. Belo Horizonte, Ed. UFMG, 2009, p. 15-100, texto no qual, inclusive, está estabelecida corretamente a centralidade da obra de Gilberto Freyre para esta tradição intelectual, embora o autor de Casa-Grande \& Senzala, ao contrário de todos os seus outros membros, tenha uma visão positiva acerca da herança ibérica e das possibilidades de uma contribuição brasileira à civilização ocidental.

${ }^{10}$ Os principais nomes desta corrente são Caio Prado Junior, Florestan Fernandes e, num nível abaixo de abstração e generalização teóricas, a maior parte da sociologia uspiana de Fernando Henrique Cardoso a Francisco de Oliveira, passando por Octavio Ianni, Maria Silvia Carvalho Franco e Francisco Weffort. Recentemente, esta perspectiva sofreu uma revitalização com os estudos teoricamente inovadores do sociólogo Jessé Souza que, inspirado em figuras como Pierre Bourdieu e Charles Taylor, desenvolveu uma hermenêutica para compreender a estrutura social de sociedades periféricas como a brasileira, tendo como um dos focos o problema da desigualdade. Mas apresenta também, como um de seus traços mais salientes, a incapacidade de pensar as instituições e os processos institucionais passíveis de reorganizar a estrutura criticada e denunciada. Desde a passagem pelo governo de Dilma Roussef, quando ocupou a presidência do IPEA (2015-2016), sua produção descambou para o militantismo, exacerbando uma perspectiva moralizante da sociedade e da política - a descrição de todas as relações como fonte inesgotável de opressão, humilhação, subjugação e tudo o mais que transforme a vida social numa espécie de novela entre algozes malvados e vítimas indefesas.
} 
anterioridade das liberdades civis em face das liberdades políticas e a reorganização estrutural do capitalismo brasileiro como meio de construir a nossa civilização foram a sua marca em um primeiro momento, cuja natureza autoritária ${ }^{11}$ foi aos poucos sendo suplantada por uma perspectiva baseada na democratização socioeconômica como forma de mudança social. $^{12}$

Não é difícil constatar que o imanentismo ralo e o seu apelo à estabilidade institucional a ser consumada por meio da cópia das instituições, sobretudo as de fora do contaminado arco ibérico, é uma atitude intelectual e política depreendida do liberalismo culturalista. Não há o que inventar, pensam. Os esquemas institucionais exitosos seguem um receituário de convergências diante do qual só cabe, aos países do Sul que procuram estabilidades, a importação e a adaptação do que deu certo no Norte.

Uma consciência constitucionalista robusta e um projeto político sério de educação figuram como a poder realizar o casamento entre o povo brasileiro, insubordinado e inculto, e a Constituição de 1988, principiológica e completa, apesar de fustigada e sodomizada pelas

\footnotetext{
${ }^{11}$ Wanderley Guilherme dos Santos, o mais eminente cientista político brasileiro, desenvolveu um dos conceitos mais importantes para se analisar o pensamento político brasileiro, o de autoritarismo instrumental: "Em primeiro lugar, os autoritários instrumentais, na designação aqui adotada, creem que as sociedades não apresentam uma forma natural de desenvolvimento, seguindo antes os caminhos definidos e orientados pelos tomadores de decisão. E desta presunção deriva-se facilmente a inevitável intromissão do Estado nos assuntos da sociedade a fim de assegurar que as metas decididas pelos representantes desta sociedade sejam alcançadas. (...) Em segundo lugar, afirmam que o exercício autoritário do poder é a maneira mais rápida de se conseguir edificar uma sociedade liberal, após o que o caráter autoritário do Estado pode ser questionado e abolido. A percepção do autoritarismo, como um formato político transitório, estabelece a linha divisória entre o autoritarismo instrumental e as outras propostas políticas não democráticas" SANTOS, Wanderley Guilherme dos. Ordem burguesa e liberalismo político. São Paulo, Duas Cidades, 1978, p. 19.

${ }^{12}$ Esta é a corrente de pensamento com o maior grau de heterogeneidade, tanto ideológica quanto metodológica. Fazem parte dela figuras como Oliveira Vianna, Guerreiro Ramos, Celso Furtado, Ignácio Rangel, Darcy Ribeiro, Mangabeira Unger. Uma maneira de compreender a ligação entre estes autores é observar que tanto no diagnóstico dos problemas brasileiros, em que o "capitalismo" não é compreendido como uma metaestrutura como o faz o estruturalismo sociológico, quanto na proposta de ação política, nenhum deles se deixa seduzir completamente por abstrações conceituais e ideológicas como o fazem o liberalismo culturalista e o estruturalismo sociológico, ambos "vidrados" nas doutrinas europeias prestigiosas do século XIX. Além disso, os construtivistas institucionais não compreendem as classes e seus interesses como uma variável independente da política, como fazem os estruturalistas sociológicos. Oliveira Vianna foi consultor jurídico do Ministério do Trabalho de Vargas e nesta condição foi o principal formulador do arranjo institucional que regulou até meados desta década as relações entre capital e trabalho no Brasil. Celso Furtado foi o primeiro ministro do planejamento da história do Brasil durante o governo de João Goulart, como o formulador de seu famoso plano trienal. Ignácio Rangel foi assessor econômico de Vargas. Guerreiro Ramos foi deputado federal pelo PTB, sendo cassado em 1964. Darcy Ribeiro foi ministro da Casa Civil do governo João Goulart e o grande formulador das políticas públicas dos governos de Brizola no Rio de Janeiro. Mangabeira Unger dirigiu a FEEM (instituição responsável por menores infratores) no governo Brizola e foi o principal formulador dos programas de governo da candidatura de Brizola nas eleições presidenciais de 1989 e 1994. Para uma exposição clássica da primeira fase deste pensamento, ver SANTOS. Ordem burguesa e liberalismo político, cit., especialmente o capítulo 1. Para uma crítica desta visão, entendida como veículo de uma nociva ideologia de estado, ver LAMOUNIER. Formação de um pensamento político autoritário na Primeira República: uma interpretação, cit.
} 
circunstâncias. O liberalismo culturalista nunca titubeou diante da assertiva de que as instituições são boas, os costumes do povo e de sua elite política é que não estão à sua altura.

Outrossim, o pan-conflitivismo anti-institucional é um cacoete herdado do estruturalismo sociológico, tendência que melhor conseguiu despertar a sensibilidade teórica contra a cupidez dos grandes conglomerados econômicos e suas blindagens institucionais. A fatalidade que acometeu ao estruturalismo sociológico com a ampliação da malha da classe média no país, com a indisposição para as aventuras revolucionárias após a Queda do Muro de Berlim, e com o ressentimento residual diante de um mundo repleto de injustiças de difícil reparo, foi a que gerou um perfil de intelectual e de ativista que está disposto a avançar na crítica às formas de vida social contemporâneas por um viés identitarista. Diferentemente do imanentismo ralo dos liberais culturalistas, essa tendência entende que o que se deve fazer é corroer as engrenagens formais do regime político viciado e esperar que, da corrosão, dê-se, espontânea e quase magicamente, a implementação da justiça.

A militância identitarista é engajada em confirmar diagnósticos de desequilíbrios, desvantagens e explorações humanas, advogando que os grupos alocados no lado predominantemente explorado e em desvantagem, na balança, convergem em interesses de suplantação das elites supostamente homogêneas que lhes são algozes. Esse expediente confere à militância identitarista a autoimagem de recrutadores do interesse universal disperso nas minorias - os agentes da transformação que pujaram com o ocaso do proletariado marxista. Destarte, a militância se alimenta de protestos e assembleias e, conscientemente ou não, age hostilizando o aparato institucional existente como quem o condena por acumpliciamento de crime - o delito de integrar a meta-estrutura denunciada como injusta.

Nesse contexto, a ideia de nação não corresponde à de um constructo facultado ao empreendimento de homens e mulheres comuns, no tempo presente. Ao contrário do que ambiciona o construtivismo institucional, a nação, enquanto ideia e projeto, figura para esse identitarismo pan-conflitivista e anti-institucional, como a própria sede imaginária dos tormentos e angústias históricos que assombram os mesmos sofredores de sempre. Essa fantasia tem custado caro, não apenas à política e à academia, mas principalmente às gerações de jovens que adquirem consciência de seu lugar no mundo sem uma identidade nacional que o contemple, em um tempo em que os Estados-nacionais continuam sendo o palco principal da coletividade humana. 
Não apenas por exclusão, mas também por virtude, o construtivismo institucional é o programa de ideias que aprecia as proporções do drama institucional no Brasil e prescreve as soluções para seus impasses. Primeiro, por sua substância filosófica: o construtivismo institucional segue a linha do institucionalismo transcendentista para o qual a contingência histórica, a política como experimento e a plasticidade como conceito modulador são componentes inseparáveis de qualquer fenômeno social e institucional. Não cabe aos construtivistas investir na estabilidade, porque estabilidade é o resultado tardio de processos institucionais e não a matriz criadora de instituições.

Segundo, por sua orientação política. A cópia institucional que entusiasma a mentalidade das elites brasileiras pressupõe haver pacotes prontos de instituições para empreendimentos civilizatórios seguros. Não os há. O construtivismo institucional enxerga receituários com desconfiança ou desprezo precisamente porque não olha para a posição do Brasil no mundo, e para suas peculiaridades, como variáveis secundárias para a conquista de um ponto de vista capaz de prover saídas eficazes para seus problemas.

Terceiro, pela constituição de seu perfil de intelectual. O intelectual construtivista não repousa por trás dos textos ou das rotinas acadêmicas. Ele ou ela atuam para testar experimentalmente a validade de suas ideias. Por isso, os construtivistas tendem a ser, além de intelectuais, homens - e desde meados do século XX, mulheres - de Estado, e só se concebem como intelectuais à proporção que acumulam, para a sua própria maturidade teórica, um sem-número de ensinamentos, advertências e incentivos que a atividade prática, e só ela, permite realizar. A aproximação dos construtivistas institucionais com as instituições não é, portanto, a de scholars tematicamente instigados; mas a de agentes e operadores.

\section{Conclusão: o futuro da democracia como construção e experimento}

A variedade de formas institucionais que a democracia pode assumir tem sido ignorada pelo pensamento político contemporâneo. A causa principal desta posição é o predomínio da prática do fetichismo institucional: a identificação de ideias abstratas, como a de democracia e a de mercado, com alguns arranjos jurídicos específicos e extremamente detalhados que lhes dão fisionomia real, mas que são apenas uma versão das possibilidades de organização da democracia e do mercado. Essa associação, em boa medida arbitrária, entre esses conceitos genéricos e algumas de suas traduções historicamente localizados nas 
experiências do Atlântico Norte, se tornou o balizador do espaço dentro do qual se pode pensar a democracia.

A esta prática fetichista, se junta no Brasil, uma outra também muito nociva: a do colonialismo mental, tal como nos referimos anteriormente. Combinadas, produzem um cenário que sonega a discussão e a imaginação das formas alternativas de organização política e econômica de nossa sociedade. Esse estreitamento do horizonte mental e discursivo acerca de nossas instituições e suas possibilidades de reorganização acaba por influenciar também a própria operação da ordem institucional vigente no país. Na última década, às limitações inerentes ao contexto da Constituição de 1988 e sua postura evasiva em relação ao enfrentamento estrutural dos graves problemas do país, justapôs-se o atalho da judicialização da política. Uma de suas consequências foi acirrar a crise do sistema político e auxiliar na eleição presidencial de Bolsonaro.

A resposta a este quadro de mediocridade institucional a que está submetida a democracia brasileira, que não consegue prover nem estabilidade nem a satisfação da maioria do país com os resultados da oferta programática realizada pelo sistema político, requer uma rebelião contra a convivência entre o imanentismo ralo e o pan-conflitivismo inconsequente, acomodados numa espécie de coalizão informal parecida com os casamentos infelizes. Essa rebelião implica a substituição das influências intelectuais responsáveis pela consciência institucional brasileira vigente. Em seu lugar deve estar a tradição que se caracteriza por conferir primazia à construção - e reconstrução - institucional. Ela o faz por não se intimidar diante do colonialismo mental praticante do fetichismo institucional.

O construtivismo institucional parte da premissa de que a organização institucional da política define as condições de reforma estrutural da ordem econômica e social. Nas circunstâncias atuais do Brasil, não parece sábio abraçar o axioma conservador segundo o qual a estabilidade política requer baixa mobilização política. Não parece razoável supor mecanismos estabilizadores que consigam fazer com que a maioria aceite calada e quieta a situação infortunada a que está submetida. Logo, o mais realista é justamente partir da realidade: $\mathrm{O}$ atual sistema político brasileiro não goza de prestígio com a maioria da população. A razão é a percepção difusa e intuitiva, porém correta, de que se trata de um arranjo operado para atender interesses de minorias organizadas contra as aspirações da maioria.

É possível institucionalizar a vontade da maioria e produzir decisões efetivamente vinculantes? Sim. Para isso é preciso um desenho institucional da política que combine 
elementos da democracia representativa com elementos da democracia direta. Essa combinação objetiva evitar a lógica dos impasses e acordos entre minorias, desligados dos interesses das maiorias, como ocorre no estilo do constitucionalismo liberal cujas técnicas se destinam justamente a desacelerar o ritmo da política para evitar a transformação da sociedade. Se invertida a lógica constitucional liberal geradora da inércia sociopolítica, o objetivo passa a ser a solução rápida dos conflitos que surgirão do esforço de atendimento às demandas da sociedade recebidas pelo sistema político.

Um exemplo concreto e fácil de ser compreendido por todos na sociedade é a introdução de regra constitucional em nosso atual regime eleitoral que permita tanto ao presidente como ao parlamento convocar, unilateralmente, eleições antecipadas, simultaneamente para ambos os Poderes, diante de impasses e crises como a que estamos experimentando agora diante da divisão do país a respeito da maneira de condução da saúde pública na pandemia pelo governo Bolsonaro. Se já dispuséssemos deste instrumento prático teríamos encaminhado solução ao atual desarranjo vivenciado por meses a fio. Os dogmas constitucionais como a separação de poderes combinado a dispositivos como o dos freios e contrapesos podem muitas vezes se mostrar incapazes de responder adequadamente a situações concretas. Ao invés de apostar em conspirações da elite política e alimentar expectativas em processos institucionalmente custosos como o impeachment, o engajamento da sociedade na solução de uma questão programática extremamente relevante mostra-se não apenas perfeitamente factível operacionalmente como politicamente mais democrático.

As melhores opções institucionais são sempre aquelas que observam atentamente a relação de seu conteúdo com o seu contexto de aplicação. É preciso imaginar alternativas que garantem mobilização política institucionalizada da sociedade, até mesmo para se evitar que as frustrações sistemáticas da vontade da maioria estimulem essa mesma maioria a buscar soluções autoritárias. Instituições definem o futuro. Construamos as nossas, com réguas e compassos meticulosamente orientados às especificidades da realidade nacional brasileira. 


\section{Referências bibliográficas}

BOBBIO, Norberto. Qual Socialismo? Discussão de uma alternativa. Rio de Janeiro, Paz e Terra, 1983.

HEGEL, G.W.F. Linhas Fundamentais da Filosofia do Direito. São Leopoldo, Ed. Unisinos, 2010.

LAMOUNIER, Bolívar. Formação de um pensamento político autoritário na Primeira República: uma interpretação. In: FAUSTO, Boris (org.). História geral da civilização brasileira: tomo 3: O Brasil republicano: volume 2. São Paulo, Difel, 1985.

. Rui Barbosa e a construção institucional da democracia brasileira. Rio de Janeiro, Nova Fronteira, 1999.

MERQUIOR, José Guilherme. Rousseau and Weber: Two Studies in the Theory of Legitimacy. London, Routledge \& Kegan Paul Ltd., 1980.

RAMOS, Alberto Guerreiro. Introdução Crítica à Sociologia Brasileira. Rio de Janeiro, Ed. UFRJ, 1995.

SANTOS, Wanderley Guilherme dos. Ordem burguesa e liberalismo político. São Paulo, Duas Cidades, 1978.

SOUZA, Jessé. A ralé brasileira: quem é e como vive. Belo Horizonte, Ed. UFMG, 2009.

UNGER, Roberto Mangabeira. Depois do Colonialismo Mental: Repensar e reorganizar o Brasil. São Paulo, Autonomia Literária, 2018. Social Theory. Its situation and Its Task. Cambridge, Cambridge University Press, 1987.

Plasticity into Power: Comparative-Historical Studies on the Institutional Conditions of Economic and Military Success. Cambridge, Cambridge University Press, 1987b.

VIANNA, Luis Werneck. A Revolução Passiva: Iberismo e americanismo no Brasil. Rio de Janeiro, Revan, 1997. 
Como citar este artigo: TEIXEIRA, Carlos Sávio G; MEDEIROS, Tiago. O Construtivismo Institucional e a Democracia Brasileira. Revista de Ciências do Estado, Belo Horizonte, v. 6, n. 2, p. 1-20, 2021.

Recebido em 13.08.2021

Publicado em 17.08.2021 